\title{
DE VUELTA SOBRE LA SEDUCCIÓN EN LOS LIBROS DE CABALLERÍAS. CON ESPECIAL ATENCIÓN A LA FIGURA MASCULINA Y EL 'DONJUANISMO'”
}

\author{
María del Rosario Aguilar Perdomo \\ Universidad Nacional de Colombia
}

El amor me guía a mi inclinación, de quien no hay hombre que se resista.

Quiero llegar a la cama, ¡Aminta!

(El burlador de Sevilla, III, 198-202)

Pa misa diba un galán caminito de la iglesia, no diba por oír misa ni pa estar atento a ella, que diba por ver las damas las que van guapas y frescas (Romance recogido en 1889)

Por los numerosos folios de los libros de caballerías se suceden escenas idílicas y amorosas que los protagonistas, damas y caballeros, viven, padecen y disfrutan en un repertorio de casuística amorosa amplio y diverso, que reaviva en muchos aspectos el amor trovadoresco y cortés, pero que también da amplias posibilidades al juego amoroso. Desde el enamoramiento de los personajes principales hasta las más diversas relaciones amorosas, los libros de caballerías recrean, revisan, reinventan y evidencian una colección considerable de episodios que muestran cómo el género, nada homogéneo en su desarrollo y evolución, va cambiando la mirada, la representación y la intención: de la reafirmación, con carácter normativo, de los comportamientos amorosos y sexuales permitidos en la sociedad cortesana que testimonia,

*Agradezco de manera especial a Nieves Baranda, Mario Botero, Ana Carmen Bueno, Juan Manuel Cacho Blecua, Pedro M. Cátedra, Jesús Duce, Javier Roberto González, José Manuel Lucía, Carmen Marín Pina, José Julio Martín Romero y Emilio Sales sus ayudas bibliográficas así como las valiosas sugerencias que me han hecho para la elaboración de estas páginas. Este trabajo se inscribe dentro de los proyectos adelantados por el Grupo de investigación Estudios de Literatura Medieval y Renacentista de la Universidad Nacional de Colombia y la Universidad de Antioquia. 
aunque con algunos deslices, el Amadís de Gaula montalviano a la admisión en sus páginas de actuaciones femeninas y masculinas que revelan una libertad sexual y amorosa ${ }^{1}$ a todas luces condenable para los moralistas del siglo XVI, que en más de una ocasión alzaron su dedo inquisidor para señalar los malos ejemplos que escondían las historias de caballeros andantes con particular referencia a las actuaciones femeninas ${ }^{2}$.

El despliegue y la variación de los motivos amorosos son tan amplios como múltiples son las formas de amar de los protagonistas de estos largos libros de aventuras caballerescas. Dentro de éstas se destacan sin embargo los numerosos artificios utilizados por damas y doncellas que recurren a todo tipo de estrategias y artimañas para obtener el amor de los héroes ${ }^{3}$, mostrando con ello las variadas posibilidades de la vivencia erótica que están muy lejos del estrecho marco del matrimonio donde en rigor se enmarcan estas experiencias durante la Edad Media y el Renacimiento. Los comportamientos de dueñas y doncellas en el campo del amor tienen, sin embargo, su contraparte masculina. Hay, en efecto, otra cara de la luna y otro rostro de la seducción. $\mathrm{Si}$ a la recatada y honesta Oriana le corresponde su Amadís y los dos ejemplifican una relación modélica por el compromiso y la lealtad mantenidos aún después de la consumación sexual, de la misma manera las doncellas seductoras, subversivas en tanto que rompen con los códigos del amor que dejaba en los hombres las iniciativas eróticas, tienen un espejo en el que contemplarse en los caballeros seductores y mujeriegos, predonjuanescos, que tienen en el Gauvain artúrico tal vez su antecedente más directo en el universo literario de la caballería y con quien tienen unas analogías indudables ${ }^{4}$. El caballero seductor e incansable requeridor de amores, que mantiene relaciones sentimentales sucesivas, escasamente duraderas, con un notorio matiz sexual y no propiamente derivadas de un proceso previo de amores, corresponde, tal

${ }^{1}$ Sobre esta particularidad del género, véase Emilio Sales, La aventura caballeresca. Epopeya y maravillas, Alcalá de Henares, Centro de Estudios Cervantinos, 2004, pp. 54-58.

${ }^{2}$ Elisabetta Samarmati ha recogido estas críticas en Le critiche ai libri di cavalleria nel cinquecento spagnolo, Pisa, Giardini, 1996.

${ }^{3} \mathrm{He}$ hecho una primera aproximación a la seducción femenina en mi trabajo «Las doncellas seductoras y requeridoras de amor en los libros de caballerías españoles», Voz y Letra, 15.1 (2004), pp. 3-24. También se han ocupado del tema Lucía Megías y Sales Dasí en «La otra realidad social de los libros de caballerías: damas y doncellas lascivas», Actes del X Congrés Internacional de l'Associació Hipànica de Literatura Medieval, ed. de Rafael Alemany, Josep Lluís Martos y Josep Miqueal Manzanaro, Alicante, Institut Interuniversitari de Filologia Valenciana, 2005, vol. 3, pp. 1007-1022. La vuelta al motivo de la seducción pretende dar una primera mirada a la contraparte de estas doncellas: el caballero donjuanesco.

${ }^{4}$ Para Y. Giraud, Gauvain «est en quelque sorte l'archétype du séducteur: témoignent ses quatre aventures dans le Conte du Graal. À ses yeux [...] l'amour pour toute belle dame est excusable parce que naturel, alors que pour une laide ce serait signe de perversité, donc peché», en «Galaor le galant chevalier», Les Amadís en France au XVI' siècle, París, Éditions Rue D’Ulm, 2000, p. 106. 
como lo ha notado Bueno Serrano, al motivo T10.4 (G) ("Man continually falling in love") del Índice de Thompson ${ }^{5}$ y tiene en los libros de caballerías el modelo por excelencia en Galaor, el hermano libidinoso de Amadís de Gaula (1508) que sorprende por su libertinaje sexual y una postura vitalista que no admite tener relaciones con una sola mujer. Este personaje que se desmarca de las pautas corteses dio origen a varias realizaciones: Rogel de Grecia en la tercera y cuarta parte de Florisel de Niquea $(1535,1551)$; Playartes un imitación muy cercana de este último en Febo el Troyano $(1576)^{6}$ y don Floriano del Desierto, en el Palmerín de Inglaterra (1547), probablemente el más refinado y moderno de todos ellos. A excepción de Galaor que sólo tendrá una dama a quien servir cuando su hermano le conceda en matrimonio a la hermosa reina de Sobradisa al final del libro IV de Montalvo, Rogel de Grecia se enamora inicialmente de Leónida y la considera su dama, Playartes de Florindia y Floriano de Leonarda; sin embargo, para ninguno de ellos la existencia de la dama se convierte en impedimento para los amores esporádicos que alivian en ellos la ansiedad que les produce el estar ausentes de sus señoras, demostrando así una visión pragmática del amor lejana a las vivencias corteses del servicio a una sola dama?

Uno y otros quitan la máscara y se revelan como la contraparte del modelo cortés que demandaba la entrega y la fidelidad a un único amor y resquebrajan los pedestales sobre los que éste se había erigido. Aunque el paradigma montalviano había establecido para el héroe una lealtad a toda prueba que se contrapone al adulterio ${ }^{8}$, en los mismos folios de la refundición realizada por el medinense se recrea la figura de un personaje como Galaor que, en

\footnotetext{
${ }^{5}$ Ana Carmen Bueno Serrano, Índice y estudio de motivos en los libros de caballerías castellanos (1508-1516), Zaragoza, Universidad de Zaragoza, Tesis doctoral, 2007, p. 100. S. Thompson, MotifIndex of Folk Literature: A Classification of Narrative Elements in Folktales, Ballads, Myths, Fables, Mediaeval Romances, Exempla, Fabliaux, Jest-Books and Local Legends, Bloomington, Indiana University Press, 1955-1958.

${ }^{6}$ Las aventuras amorosas de este personaje, que se relaciona con Florindia, Garinia. Filisea, Arlaya y un par de doncellas más cuyos nombres no se mencionan, son en su mayoría un calco de las de Rogel de Grecia; por ello no será tenido en cuenta en este análisis de los caballeros donjuanescos. Véase al respecto el estudio introductorio de José Julio Martín Romero a su edición de Febo el Troyano, Alcalá de Henares, Centro de Estudios Cervantinos, 2005.

${ }^{7}$ Desde este punto de vista, la seducción implicaría, en los tres casos mencionados, el adulterio; sin embargo -y en sentido estricto- no todo caballero adúltero puede ser incluido en el grupo de los donjuanes. Lo ha anotado también Elami Ortiz en «El motivo del caballero seductor en Amadís de Gaula y Lisuarte de Grecia de Feliciano de Silva», Amadís y sus libros: 500 años, ed. de Aurelio González y Axayácatl Campos, México, El Colegio de México, 2009, p. 184.

${ }^{8}$ Así lo recuerdan también José Manuel Lucía y Emilio Sales en su trabajo «La otra realidad social en los libros de caballerías. De los “desamorados" a los adúlteros», Medievalismo en Extremadura: estudios sobre literatura y cultura hispánicas de la Edad Media, ed. de J. Cañas M., F. Grande Q., J. Rozo D., Cáceres, Universidad, 2009, pp. 527-544.
} 
su condición lasciva, representa la ruptura del amor caballeresco ${ }^{9}$ al dejarse llevar por unos excesos pasionales que en la mentalidad de la época estaban asociados tanto al temperamento colérico como al sanguíneo ${ }^{10}$. Juan Huarte de San Juan en su Examen de ingenios para las ciencias (1575) señala en el proemio al lector: el colérico es el hombre que «según la potencia generativa, se pierde por mujeres ${ }^{11}$. Más adelante, subraya que «las costumbres ordinarias de los hombres calientes y secos [los coléricos] en el tercer grado son ánimo, soberbia, liberalidad, desvergüenza, y hollarse con muy buena gracia y donaire; y en caso de mujeres, no tienen rienda ni moderación ${ }^{12}{ }^{\text {. También }}$ el Arcipreste de Talavera en su Corbacho caracterizaba a los coléricos como «ardientes como fuego». En este sentido, es muy significativo que otro de los donjuanes caballerescos, Floriano del Desierto, sea descrito por el narrador como un hombre de naturaleza colérica, condición que se descubre no sólo en la ira que se apodera de él durante el combate que mantiene con su hermano Palmerín (I, 86) sino también en sus numerosas conquistas amorosas.

Durante la Edad Media y el Renacimiento la idea predominante era que el temperamento colérico era temible, pues entre otros caracteres se asociaba a la

${ }^{9}$ En su lectura de la figura de don Juan, Ramón Pérez de Ayala (Las máscaras, 1919) 1lamaba la atención justamente sobre cómo el personaje de Tirso de Molina significa la disolución de ese tipo de amor de ascendencia provenzal, hecho que para el ensayista tiene como consecuencia el destronamiento de la mujer. El texto puede consultarse en el apéndice III de la edición preparada por Andrés Amorós de Tigre Juan y Curandero de su honra, Madrid, Castalia, 1980, pp. 458-503. Desde este punto de vista, los seductores caballerescos son claramente precursores del donjuanismo.

${ }^{10}$ Alfonso Martínez de Toledo en el Arcipreste de Talavera o Corbacho indicaba que los inclinados a tratos pasionales están dominados por un temperamento sanguíneo. En el apartado dedicado a la complexión del hombre «sangino» indica que «este tal es alegre hombre, placentero, riente y jugante» (Tercera parte, cap. II, p. 206, ed. Michael Gerli, Madrid, Cátedra, 1981), para más adelante añadir que con respecto a las cualidades del hombre dominado por este humor que «es mucho enamorado e su coraçón arde como fuego, e ama a diestro e a siniestro; e quantas vee, tantas ama e quiere, e con todas mucho alegre» (Tercera parte, cap. VII, p. 212). De temperamento sanguíneo es Juan Ruiz, Arcipreste de Hita, cuya descripción física se encuentra entre los versos 1485-1489 del Libro del buen amor. De este aspecto se han ocupado, entre otros, María Rosa Lida de Malkiel, «Notas para la interpretación, influencia, fuentes y texto del Libro de buen amor», Revista de Filología Hispánica, 2 (1940), pp. 105-150, pp. 124-126 y Peter Dunn, «De las figuras del arçipreste», en «Libro de buen amor» Studies, ed. G.B. Gybbon-Monypenny, Londres, Tamesis, 1970, pp. 79-93, p. 85.

${ }^{11}$ Cito por la edición Guillermo Serés, Madrid, Cátedra, 1989, p. 172. Llama la atención sin embargo -tal como me lo ha hecho notar Juan Manuel Cacho- que siguiendo también a Huarte de San Juan se caracterice a don Quijote como hombre de temperamento colérico y a la vez el personaje se distinga por su castidad. El problema que se plantea es interesantísimo, aunque no puedo ocuparme de él en estas páginas.

${ }^{12}$ Huarte de San Juan, ed. cit, p. 620. También Giambattista della Porta, el más importante fisionomista de los siglos XVI y XVII, señala en su tratado De Humana Physiognomia (1586) que es posible conocer los hábitos de los hombres por los humores y relaciona los lujuriosos con el temperamento colérico (Libro I). Incluso en el libro IV hace una descripción de los rasgos físicos de los lujuriosos y de los adúlteros (pp. 534-535). He consultado la traducción francesa de 1655 impresa en Rouen en la imprenta de Jean y David Berthelin, accesible en línea en Google Books. Una descripción general del contenido del libro de Della Porta puede verse en Julio Caro Baroja, Historia de la fisiognómica, Madrid, Istmo, 1988. 
pasión y a los afectos sensuales, tal como lo había contemplado Aristóteles en su Ética a Nicómaco y Séneca en el tratado titulado De ira ${ }^{13}$, obras conocidas en la Edad Media desde el siglo XIII. El filósofo griego fue decisivo además en la noción de templanza y continencia que desarrollaron los escolásticos, que establecía un control sobre los apetitos en particular los relacionados con el gusto, el tacto y la sexualidad (Ética, libro III). De acuerdo con Payer ${ }^{14}$, la visión aristotélica fue complementada con los planteamientos de Cicerón que señalaban que mediante la virtud de la continencia se podía gobernar el deseo. De esta manera, la templanza se relacionó particularmente con la regulación de la conducta sexual y los bajos instintos, con el dominio de los apetitos o afectos. Es claro además que, en relación con la caballería, para Ramón Llull en su Llibre de l'orde de cavallería sus miembros debían apartarse de la lujuria ${ }^{15}$ mientras que, en el código amoroso, Andrés el Capellán recalcaba que el «amor comporta castidad, pues aquel al que le iluminan los rayos del amor apenas puede pensar en los lazos de otra que no sea su amante ${ }^{16}$. Sin embargo, ni la filosofía moral, ni los códigos caballerescos y amorosos, parecieran disuadir del comportamiento lascivo a los galaores, como tampoco impidieron que los autores del género trazaran la caracterización de estos mujeriegos en las páginas de sus libros. De hecho, aunque la incontinencia sexual era condenable desde el punto de vista de la filosofía moral y la religión cristiana ${ }^{17}$, la literatura caballeresca recreó estas figuras masculinas, promiscuas en esencia, sobre cuyo comportamiento se guarda silencio, entre otras razones, debido a la condición permisiva de la sociedad medieval y renacentista hacia ciertos comportamientos masculinos. No se encuentra en estos libros, estrictamente, una crítica o un juicio moral a la conducta de los caballeros casquivanos y ni a sus malas mañas amatorias, pues los rígidos marcos en los cuales se concebía la naturaleza de los sexos excluían al hombre de la culpa mientras que a la mujer le atañía mayor responsabilidad en cuestiones venéreas. En ese aspecto, el didactismo brilla por su ausencia: los seductores no reciben un castigo ejemplar. Sin embargo,

\footnotetext{
${ }^{13}$ De la recepción de Séneca en España se ha ocupado Karl Blüher, Séneca en España. Investigaciones sobre la recepción de Séneca en España desde el siglo XII hasta el siglo XVII, Madrid, Gredos, 1983.

${ }^{14}$ Pierre Payer, The Bridling of Desire. Views of Sex in the Later Middle Ages, Toronto, University of Toronto Press, 1993, pp. 136-141.

${ }^{15}$ Ed. de Albert Soler i Llopart, Barcelona, Barcino, 1988.

${ }^{16}$ Andrés el Capellán, Tratado sobre el amor, trad. de Inés Creixell, Barcelona, Sirmio, 1990, p. 62.

${ }^{17}$ De hecho la lujuria es uno de los vicios que debe combatir el hombre y el buen caballero. Así se resalta por ejemplo en la Peregrinación de la vida del hombre, conocido también como El Cavallero del Sol de Pedro Hernández De Villaumbrales (Medina del Campo, Guillermo de Millis, 1552), libro de caballerías a lo divino: «cuando ya comienzan las potencias del alma a despertar, la razón a discernir y conocer el bien y el mal, los ojos a ver, las orejas a oír, y la lengua con discreción a hablar, llega por la posta otro mayor trabajo, que es una continua batalla con los desordenados deseos de la carne», ed. digital disponible en la Biblioteca Virtual Cervantes.
} 
la liviandad del carácter de estos seductores sí que se reconoce por parte de otros personajes; son en la mayoría de los casos las doncellas, algunas de las cuales dudan o se niegan a entregarles su amor a los enamoradizos de turno, quienes identifican su condición infiel y desleal. Don Rogel, por ejemplo, pasa por el trance de verse rechazado por Brenia en dos oportunidades, pues ella ha adivinado la deshonestidad de sus amores luego de ver cómo ha flirteado en su presencia con Oranda y la ha convertido en su amante ${ }^{18}$. Tampoco Galaor, su antepasado, se escapa de este tipo de señalamientos: en el libro segundo de la Cuarta parte del Florisel de Niquea, Amadís reprocha a su hermano cuando lo encuentra en la cámara de un castillo acostado con una doncella y le dice: «-En mal punto señor hermano vos tornéis a la primera edad, que ya yo tenía pensado que avíades perdido estas mañas» (II, 84 , fol. 148v) ${ }^{19}$.

Fácilmente reconocible es también la naturaleza incontinente y lasciva de Floriano en el Palmerín de Inglaterra. Cuando Leonarda, su enamorada, se entera por Polinarda de la llegada de Targiana a la corte de Constantinopla, con quien el caballero había mantenido un devaneo tiempo atrás, «túvole por hombre sin fe y sin amor, y sin ley, y desamorado por estremo, pesándole de tener puesto su amor en quien no sabía tener á ninguno $»^{20}$. La doncella tiene certeza de su escasa lealtad al rememorar que el Caballero del Salvaje «anda por España con muchas mujeres tras sí, mostrando amor á todas» (II, 21, p. 247); y por ello se pregunta si puede ser un enamorado sincero y auténtico: «no sé, quien en tantas partes le reparte, cómo en alguna le puede tener cierto y seguro» (p. 247). Su preocupación está fundada y así lo demuestra la aventura de las cuatro damas francesas estudiada por Syvia Roubaud ${ }^{21}$, en la cual Floriano testimonia su clase sin ambages: «poniendo los ojos en una, allí se

${ }^{18} \mathrm{La}$ inconstancia y la mudanza en los amores es lo que recrimina la doncella al caballero: «[...] tan presto me dexastes por la que vino, y más presto, ella partida de vós, la tenéis olvidada; y más que sandía sería yo si tal escarmiento no me avisasse. —Vós tuvistes la culpa desso - dixo él. —No sé si tuve la culpa -dixo ella-, mas a lo menos seréis seguro que no tenga la pena, amando cavallero que tan presto se muda», Feliciano de Silva, Tercera parte del Florisel de Niquea, ed. de Javier Martín Lalanda, Alcalá de Henares, Centro de Estudios Cervantinos, 1999, cap. 117, p. 360. Todas las citas proceden de esta edición.

${ }^{19}$ Feliciano de Silva retoma la misma caracterización que ya había ofrecido Rodríguez de Montalvo cuando describe el segundo encuentro sexual de Galaor (p. 397); de esta manera se mantiene intacta la personalidad del caballero. También Rogel de Grecia, el heredero de su actitud hedonista, se servirá de sus mañas para seducir a dueñas y doncellas. De los vínculos y semejanzas entre ambos miembros del linaje amadisiano se ha ocupado José Julio Martín Romero, «Fidelidad sentimental y catarsis amorosa en el ciclo de Amadís de Gaula», Revista de Literatura Medieval, 22 (2010), pp. 155-184.

${ }^{20}$ Francisco de Moraes, Palmerín de Inglaterra (1547-1548), en Libros de caballerías. Segunda parte, ed. de Aldolfo Bonilla y San Martín, Madrid, NBAE, 1908 (II, 21, p. 246-247). Citaré en adelante por esta edición. Existe edición reciente del primer libro preparada por Aurelio Vargas Díaz-Toledo, Alcalá de Henares, Centro de Estudios Cervantinos, 2006.

${ }^{21}$ En su artículo «Juego combinatorio y ficción caballeresca: un episodio del Palmerín de Inglaterra», Nueva Revista de Filología Hispánica, 24 (1975), pp. 178-196. 
le olvidaban todas las otras; puestos en otra, acontescíale lo mismo» (II, cap. 40, p. 302). Pero tal vez donde es más evidente la condición subversiva de Floriano con respecto al código de sumisión y lealtad a la dama es en el bello y poético episodio de las lágrimas de Brandisia, una ordalía amorosa que lleva a la corte de Constantinopla una doncella que porta una copa en la que los caballeros podrán contemplar en las lágrimas allí depositadas la imagen de su amada. El perturbador Floriano toma la copa en sus manos pero su «desamor es de tanta fuerza» que, como pronostica la doncella de Tracia, la copa se torna más negra todavía:

Luego dio la copa á Floriano, que se quiso también ver en ella, y puniendo los ojos en las lágrimas, vido gran multitud de mujeres con los semblantes airados, y á Targiana y Arnalta, princessa de Navarra, entrellas, á su parecer mucho más airadas que todas las otras. «¿Qué veis allá? dijo la doncella de Tracia, ¿halláis por ventura la paga del merecimiento de vuestras obras?» «Paréceme, dijo Floriano, según lo que á vos veo, que ya no me favoreciéredes con que os sirviesse muy bien, pues yo no dejo de creer que vos y todas las otras de vuestro nombre serían mejor servidas de mí que de otros algunos que en la copa harían mejores muestras» (I, 92, p. 163).

De otra parte, ninguno de los donjuanes de estas páginas se muestra preocupado por los efectos que sus deslices podrían acarrear en el ardor guerrero, su capacidad de combate y la fuerza de su ánimo. Tal vez por ello sus escarceos se introducen en períodos de inactividad, en desplazamientos por las florestas o como recompensa a su lucimiento en las armas al servicio de una dama. En ciertas ocasiones, además, se introducen en el entramado en momentos de distensión narrativa y cubiertos, en algunos casos, con un matiz lúdico. Es así como la primera aventura amorosa de Galaor $^{22}$, que tiene como antesala el ingreso a un huerto por una pared donde luego encontrará una hermosa doncella peinándose los cabellos (I, 12), tiene lugar después de que vence a Aldabán y retorna así las tierras a Gandalaz. Aunque el episodio parece gratuito, a la primera hazaña caballeresca le corresponde la iniciación sexual del personaje que, como ha resaltado Cacho Blecua, está acompañado de elementos simbólicos y eróticos (el huerto, la pared que debe subirse, la acción de peinarse los cabellos, la guirnalda) ${ }^{23}$; de esta manera -como ocurre

${ }^{22} \mathrm{Ha}$ sido estudiada por Juan Manuel Cacho Blecua, en Amadis: heroísmo mítico cortesano, Madrid, Cupsa, 1979, pp. 93-98. Véase también Sylvia Roubaud, «La Forêt de Longe Attente: amour et mariage dans les romans de chevalerie» en Amours légitimes, amours illégitimes en Espagne (XVİ-XVIt siècles), ed. de A. Redondo, París, Pub. de la Sorbonne, 1985, pp. 262-266 e Yves Giraud, art. cit.

${ }^{23}$ Ob. cit., pp. 95-96. 
con otros donjuanes- la aventura amorosa se constituye en recompensa por una actuación ejemplar en las armas. A pesar de la discreción del narrador y de la glosa moralizante posterior, el lector puede saber que Galaor «folgó con la donzella aquella noche a su plazer ${ }^{24}$. La parquedad no deja de lado entonces un aspecto fundamental del episodio que está presente también en todas las aventuras amorosas de los donjuanes caballerescos: el disfrute erótico y la vivencia de una sexualidad libre y autónoma por parte del hombre y de la mujer que se mantienen así al margen de las coerciones patriarcales ${ }^{25}$.

La segunda aventura amorosa de Galaor está cifrada de nuevo alrededor de un servicio prestado a una dueña, hija de Lelois el Flamenco, que se encuentra prisionera en un castillo. Allí arriba el caballero en busca de quien le cure una llaga producto de la refriega con unos caballeros a la salida del castillo de Aldeva, su primera amiga. La llaga corporal que aqueja a Galaor se transforma en herida de amor y la libertad de la dueña prontamente se traduce en la prisión del caballero a causa de la mujer que le había parecido «a maravilla fermosa»; así lo expresa el caballero: «Señora, yo os delibré de prisión y só yo en ella caído si me vos no acorréis» (I, 15, p. 397). La cortesía de sus palabras cautiva a la dueña y, así, «con tales razones amorosas y de buen talante, y con las mañas de don Galaor, y con las de la dueña, que por ventura a ellas conformes eran, pusieron en obra aquello que no sin gran empacho deve ser en escrito puesto» (p. 397, el subrayado es mío). Sobresale en el episodio el diálogo cómplice del caballero y la dueña, así como la reciprocidad en el deseo y la libertad en la conducta de ambos. En ese sentido es importante tener en consideración dos aspectos: 1) las doncellas involucradas en los procesos de seducción de estos mujeriegos no son descritas como lujuriosas, que era lo habitual en los tratados morales y 2) no se vislumbra en ellas una preocupación por la honra como sí ocurre por ejemplo con las mujeres seducidas por el don Juan de Tirso, de tal manera que no asoma en ellas una dependencia del código del honor o un dilema entre el deseo y la honra.

La gentileza y la personalidad cautivadora se repiten en el tercer encuentro amoroso del hermano de Amadís, en este punto de la obra ya claramente singularizado como un seductor ${ }^{26}$. El esquema narrativo de sus escarceos

${ }^{24}$ Garci Rodríguez de Montalvo, Amadis de Gaula, ed. de Juan Manuel Cacho Blecua, Madrid, Cátedra, 1987-1988, vol. 1, p. 354. Citaré siempre por esta edición.

${ }^{25}$ Son interesantes las observaciones que sobre este aspecto hacen Vázquez García y Moreno Mengíbar en Sexo y razón: una genealogía de la moral sexual en España (siglos XVI-XX), Madrid, Akal, 1997, p. 369.

${ }^{26}$ La imagen perdurará en el ciclo amadisiano. Así, en la Cuarta parte del Florisel de Niquea (Salamanca, Andrea de Portonaris, 1551) se señala su condición: «Por sabiduría tendréis lo que hizo el rey de Sobradisa, don Galaor, [...] amar a cuantas lo querían amar » (fol. 141r). 
amorosos anteriores se confirma, pues Galaor le presta un servicio a la doncella Brandueta al vengar la muerte de su padre y gracias a éste recibe una recompensa sexual. Aquí, como en las anteriores, el donaire y la gracia de Galaor juegan un papel fundamental, pues estas cualidades aunadas a su belleza enamoran a la bella doncella que «se pagó dél mucho más que de ninguno otro que jamás viera» (I, 25, p. 497). Es precisamente la personalidad encantadora de Galaor y sus dotes como seductor las que lo librarán a él y a su hermano Amadís de la prisión de Madasima, señora de Gantasi, con quien el caballero pasa la noche pues ella ha quedado prendada de su belleza y sus buenas maneras. Pero su gusto por las mujeres llega a tal punto que no es capaz de percibir el engaño que le prepara Dinarda, la sobrina de Arcalaús, en tanto que en él es más fuerte el deseo que la prudencia ya que, aunque sabe que la doncella busca la muerte de su hermano Amadís, termina declarando que ella es «la muger de cuantas yo vi que más me ha contentado y no la quiero partir por agora de mí» (III, 69, p. 1070).

Es evidente que, a diferencia de otros caballeros amadisianos, Galaor tiene un aire fascinante y atrayente y por ello no tiene necesidad de mentir, de engañar o de prometer nada a las dueñas y doncellas que conquista. Su actuación está dirigida a embargar y cautivar el ánimo de las mujeres que él desea; por ello, además de su condición guerrera y el ejercicio de las armas, su rasgo -como otros de su especie- es la incesante seducción de la que hablara Kierkegaard en varios de sus ensayos ${ }^{27}$. Este carácter distintivo determina que el caballero se mantenga en constante movimiento en la búsqueda de aplacar sus deseos, que esté siempre atento a la posibilidad; sus ímpetus no pueden detenerse o domesticarse hasta el punto de que ni siquiera el matrimonio con la bella reina de Sobradisa le da reposo, pues la serenidad del amor conyugal le resta el movimiento que caracteriza al seductor. Aunque Rodríguez de Montalvo convierte a Galaor en un caballero casto gracias a las nupcias con Briolanja y subraya que él «pagóse tanto della y tan bien le paresció, que ahunque muchas mugeres avía visto y tratado como esta historia donde dél habla lo cuenta, nunca su coraçón fue otorgado en amor verdadero de ninguna, sino desta hermosa reina» (IV, 121, p. 1588), el hermano de Amadís vuelve a dar muestras de su condición rijosa, como diría don Quijote, en la Cuarta parte del Florisel de Niquea, cuando de camino a un castillo intenta seducir a una doncella que lo rechaza a causa de su edad. La respuesta de Galaor indica con claridad la realidad del deseo amoroso, porque según él

${ }^{27}$ El filósofo danés dedicó numerosas reflexiones al tema de la seducción y el erotismo, entre ellos El diario de un seductor y «El erotismo musical», Estudios estéticos I. Diapsalmata, traducción de D.G. Rivero, Málaga, Ágora, 1996, pp. 93-227, este último dedicado a la figura literaria de don Juan. 
este «mal no perdona ninguna edad» (II, $84,147 \mathrm{r}$ ) y por eso lo lleva a seguir insistiendo y a bromear con la doncella, pues como él mismo confiesa cuando ella le recrimina la falta de lealtad hacia Briolanja él nunca negó amor a quien le quisiese dar el suyo. Es claro que incluso al final de su trayectoria, Galaor intenta seducir con las palabras, después con los actos y, por supuesto, con su belleza, que subyuga a pesar de la edad. Es lo que finalmente logra a la llegada de un castillo donde pasará la noche después de su fracaso anterior. De esta manera, lo que parecía «la belle fin du séducteur» ${ }^{28}$ en el epílogo del libro IV de Montalvo no es tal en la continuación de Feliciano de Silva, pues en el castillo ve una hermosa doncella -que «lo miró y pareciéndole bien aunque viejo»- con la que, en medio de risas, concierta una cita en su recámara, donde «tomándola en sus braços gozó gran pieça de sus amores» (148r).

Algunos de los elementos que se repiten en las aventuras amorosas de Galaor aparecen asimismo en los episodios de este corte protagonizados por don Rogel de Grecia ${ }^{29}$; en la mayoría de ellos se acentúa el tono risueño y la particular maestría del caballero en el manejo de la palabra y en la seducción, cualidades que acompañan su atractivo físico ${ }^{30}$. Las primeras muestras de su galantería se constatan en la conversación que adelanta con tres doncellas, Sinda, Galinda y Sirea, de camino a un palacio, luego de haberlas liberado de tres caballeros que querían forzarlas. Durante el trayecto, ellas le solicitan que, al modo de Paris, decida cuál de las tres es la más bella. La ocasión no puede ser más oportuna para descubrir su naturaleza, evidente en la respuesta del caballero: «-Pues que a mí lo dexáis yo os quiero a todas tres [...] que a todas tres os quiero servir, pues Dios tan buena me la deparó» (III, 65, p. 197). El tiempo pasado con las doncellas, lleno de gozos y burlas como señala el narrador, sirve de marco anticipatorio a los primeros amores de don Rogel. Se trata de Sardenia, señora de los Cuatro Castillos, doncella de poca edad que no «atendía sino en aver plazer» (p. 199). Con ella, como rasgo persistente en el resto de sus conquistas, manifiesta su condición galante y seductora:

\footnotetext{
${ }^{28}$ Giraud, art. cit., p. 105.

${ }^{29}$ Sobre este personaje véase, Martín Romero, «Fidelidad sentimental», art. cit., y Sales Dasí, ob. cit., p. 54.

${ }^{30}$ Feliciano de Silva lo describe así en la Tercera parte del Florisel de Niquea: «Él salió de mediana estatura, muy bien proporcionado y hecho, con tanta magestad en la persona y gracia en las palabras que a todos los de su tiempo aventajó. Era tan hermoso de rostro cuanto todos los de su tiempo. El rostro tenía muy blanco y los ojos muy hermosos y negros, las pestañas tan largas que cuando abaxava los ojos hazían hermosas sombras en sus mexillas; las cejas negras y muy bien puestas; el cabello avía castaño escuro; las narizes algo afiladas y muy bien hechas; la hermosura de su boca fue de tan subido color con la blancura de sus dientes que a la de la princesa Niquea fue comparada en igualdad de hermosura; la barva de la color de los cabellos» (III, p. 11).
} 
-Mi nombre es, mi señora, -dixo él-, el Vencido de Sardenia, que tal estoy yo de vuestra fermosura.

Ella riendo dixo:

- ¿No tenéis otro nombre sino éste?

- Mi señora, no -dixo él-, en cuanto no cobrare el poder que con vuestra vista perdí.

-Pues ¿qué haremos -dixo ella- para que lo cobréis?

—Doleros de mí-dixo él (III, 66, p. 200).

Como en el caso de Galaor, la iniciación sexual de Rogel de Grecia está precedida de una acción en armas, pues el caballero se ha visto obligado a participar en un paso, instaurado por la propia doncella, en el que desarzona a diez contrincantes. Así, una acción que parece causa del azar, complementa el comienzo caballeresco del personaje pues el triunfo en las armas tiene a su vez una recompensa sexual en la que las palabras preliminares juegan un papel fundamental: la conversación ha cautivado a la doncella quien envía por él para que pase la noche en su aposento. Rogel llega así a una hermosa cuadra donde «halló a Sardenia en un rico lecho echada a la luz de dos velas de cera que en dos candeleros de plata estavan, que la hazían tan fermosa que en demasía se pagó d'ella don Rogel [...] E assí la gozó toda la noche» (III, 66, p. 201). Sin embargo, a diferencia de Galaor, que encuentra el amor al final de su trayectoria y luego de un intenso recorrido pasional en el que se cuentan seis mujeres distintas, Rogel se enamora de la infanta Leónida después de su iniciación sexual con Sardenia. El encuentro con la doncella ocurre en la Ínsula de Gazén, adonde ha llegado camino de Guindaya y después de haberla liberado con ayuda de Falanges y Alastraxerea. Nuevamente el caballero hace uso de su destreza con la palabra y le declara su amor mientras pasean juntos por la deleitosa huerta del castillo:

- ¡Ay de mí!, que la gloria qu'el alma, mi señora, rescibe en tener en sí al natural la vuestra gran hermosura con fuerça de tal resplandor, el coraçón como estopas abrasa puesto ante el espejo de mi alma donde los rayos de vuestra hermosura contino pueden salir. ¡O $\mathrm{O}$, mi señora! ¡Y en cuán gran prisión me pusistes y cuán pequeña es de la que salistes en comparación de la que yo siento, pues las guardas de la vuestra eran hombres que se podían y pudieron sojuzgar, mas las guardas de la mía es sola vuestra voluntad a quien se ha dado la mía! ¡Ay de mí, señora!, si en vós no ay algún sentimiento para sentir el que a mí sobra en sentillo tanto cuanto me faltan palabras para dezillo, suplico's, mi señora, que en pago de mis dolores solo alcance licencia de la vuestra merced para llamarme vuestro cavallero y tenerme por tal, para que 
en gloria de tales pensamientos las de mis hazañas se pueda acrecentar como hechas en tal nombre (III, 68, p. 210).

La referencia a la prisión del caballero causada por el amor así como a los rayos que salen de la hermosura de la doncella y que se posan en su alma evidencia el uso de una terminología cortés y neoplatónica ${ }^{31}$, que se refuerza con la súplica y el ruego como recursos para doblegar a la amada. Pero a diferencia de su antepasado, Rogel recurre al engaño, a la mentira y no tiene ningún reparo de orden moral. Su talante lo lleva a buscar la satisfacción del deseo con la posesión de la dama -aunque no lo consiga en el caso de Leónida - y luego, a diferencia de los verdaderos amadores, se disipa el atractivo que trae como consecuencia el abandono, la vuelta al movimiento y la conquista posterior. El contentamiento que implica la seducción y el consecuente gozo sexual posibilita que se asiente en él la destemplanza ocasionada por la ausencia de su enamorada, Leónida. Así lo confiesa a Filisel, su compañero de aventuras, después de preguntarle si está interesado en Agresta, la donce1la que los acompaña: «Si vós no tenéis amor a esta donzella yo lo procuraré tener con ella, porque me semeja muy bien para poder templar algo la pena que la ausencia de mi señora me da» (Cap. 96, p. 301).

El hijo de Florisel de Niquea y de la princesa Helena es, sin duda, un personaje que se aparta de la norma impuesta por las convenciones amorosas. Su habilidad para darle otra vuelta de tuerca a los preceptos corteses y su premura para satisfacer sus deseos y la poca paciencia para el largo cortejo que exigía el servicio amoroso es evidente en varias de sus conquistas. Este personaje construido por Feliciano de Silva es, pues, exponente de una visión distinta del amor (¿naturalista?), cuya postura vital tiende al hedonismo y contrasta con la de la mayoría de los miembros de su linaje, constituidos en las diferentes partes de la saga amadisiana como modelos de lealtad y acatamiento a sus respectivas damas ${ }^{32}$. En contraste con algunos de sus parientes,

\footnotetext{
${ }^{31}$ José Julio Martín Romero ha estudiado cómo se reflejan las concepciones derivadas del amor neoplatónico en las obras de Feliciano de Silva, particularmente en las distintas partes del Florisel de Niquea, en su artículo «Del fin'amors al neoplatonismo: amor y caballería en la narrativa caballeresca hispánica», Tirant, 11 (2008), pp. 119-142.

${ }^{32}$ Así se lo recuerda Filisel cuando Rogel pretende a la doncella Agresta en la Tercera parte del Florisel de Niquea: «[...] y pues vós usáis con él de sinrazón en no tener la lealtad que vuestros agüelos tuvieron en amar, no's maravilléis si rescibierdes la paga fuera de la razón de amor» (II, cap. XCVI, p. 301). En la Cuarta parte del Florisel es Galaor quien es puesto en tela de juicio por una doncella a la que el rey intenta seducir: «- ¡Para Santa María! -dixo la donzella- que muy al revés es esto de lo que siempre a mí me han dicho. - ¿Qué os an dicho a vos? -dixo el rey. - Ánme dicho -dixo ella-, que todos los del linage del rey Amadís eran muy leales a sus mugeres. - Essa sandez - dix él- a osadas que no la dixessen de mí, que nunca la acostumbré, ni negué amor a quien me quisiesse dar el suyo» (II, 84, fol 147r-v).
} 
Rogel reconoce que para él la fidelidad amorosa es una sandez. Esta conducta censurable induce a su compañero el príncipe Brianges a cuestionar el amor que dice sentir por Leónida:

— ¿Cómo, en mal punto, amando tan hermosa infanta le guardáis tan poca lealtad?

-Y vós -dixo don Rogel- ¿por qué no la guardastes con la donzella que tomamos a los tres cavalleros?

- Pues entonces - dixo don Brianges- no erré yo a mi señora que aún no la avía visto.

- Tampoco aora veo yo a la mía - dixo don Rogel- ni ella vee menos lo que yo hago si vós no se lo dezís, que de Sarcira bien seguro estoy que no lo dirá.

- Tampoco vós diréis -dixo don Brianges- que os semejáis nada a vuestros abuelos en lealtad.

-Nunca fui aficionado a esas sandezes -dixo don Rogel. (cap. 121, p. 369).

El espíritu hedonista del caballero y su indomable apetito sexual impiden que se mantenga fiel a su Leónida. Muy por el contrario, el derrotero amoroso de don Rogel incluye además de Sardenia, a 1) Agresta (cap. 96) a quien se otorga con desfachatez como su caballero cuando pocas páginas atrás le ha dicho lo mismo a Leónida; 2) Oranda (cap. 115); 3) una dueña recién casada que queda prendada y decide «gozar de él» (cap. 166); 4) Sarcira, a quien engaña diciéndole que no ha amando nunca a otra doncella con la intención de doblegar su voluntad férrea (cap. 121) y a la que incluso llega a forzar pues «contra la voluntad d'ella tomó la prenda que para ser amado de tal donzella se suele tomar» (p. 371); 5) Persea, cuya conquista comienza con el motivo del cazador cazado y que retoma el tópico del muro por el que se debe trepar para acceder al jardín donde se encuentra la doncella ${ }^{33}$. En los interludios del cortejo a Persea Rogel revive los amores con Sardenia, su primera amiga, ya que «no pudo tanto la prenda del amor que dado tenía a la infanta [Persea], junto con la natural falta de lealtad que en él avía, que no le moviesse más la memoria de la gloria del tiempo que de los amores d'esta donzella pudo gozar» (cap. 165, p. 489). 6) Salderna, la reina de Galdapa, que se prenda de él al observar su atractivo físico (cap. 167) y se convierte en la última aventura erótica del caballero en la Tercera parte. 7) Arquisidea, de quien se enamora al inicio de la Cuarta parte (I, cap. X), cuando asume la identidad del pastor

\footnotetext{
${ }^{33}$ La seducción de Persea es tal vez el mayor reto amoroso al que debe enfrentarse don Rogel a causa de las negativas persistentes de la doncella; de hecho el héroe logrará doblegarla sólo después de varios intentos. Martín Romero ha revisado con detalle cómo cambia la estrategia de seducción de don Rogel con la infanta Persea, art. cit.
} 
Arquileo y con quien a la postre se casará (II, cap. 67), no sin antes haber recibido como recompensa a 8) Argentaria luego de haber superado la Aventura del Cubo del Espejo y 9) concebir un hijo con ella (I, XXI) $\left.{ }^{34}, 9\right)$ para posteriormente enamorarse de Sinestasia, conocida como el retrato de Arquisidea.

La trayectoria amorosa de este personaje astuto, engañador e irremediablemente seductor se cierra, pues, con el matrimonio con Arquisidea, quien decide casarse con él a pesar de haber contemplado aterrada en la aventura mágica de Finisbel y Fenisbela las numerosas cabezas de las damas que el caballero griego ha amado (IV/I, cap. 47). El matrimonio conduce a la última etapa de su recorrido perpetuo: significa la rectificación de su conducta y la aceptación del código cortesano de la fidelidad y de la unión matrimonial. Su nueva atalaya vital pareciera corroborarse en la ordalía amorosa que le permitirá emanciparse de su pasado: se trata de la aventura de los reyes de la Ínsula de Gandalia cuyos mantos encantados posibilitaban que quien se cubriera con ellos se transformara en su amado (IV/II, cap. 68). Gracias a ello, el promiscuo e irresoluto caballero demuestra ser el fiel amante de Arquisidea y testimonia el abandono definitivo de su estilo de vida anterior y la revelación de sus sentimientos ${ }^{35}$. Este Rogel domeñado finalmente por el amor y el matrimonio, encauzado en las pautas corteses luego de su larga e incontinente trayectoria, está ya muy distante del que había afirmado refiriéndose a sus devaneos amorosos: «era gran simpleza dejar de gozar lo que gozaba, por sandeces de lealtades de amores, y que antes para templar el amor, cuando era grande en alguna parte, era bien gozar de tales pasatiempos ${ }^{36}$.

El más moderno y libertino de los seductores es a todas luces Floriano del Desierto, la antítesis de su hermano Palmerín, un caballero subversivo, como lo ha calificado Ruiz de Conde $^{37}$, que cuartea por completo los ideales corteses

${ }^{34} \mathrm{La}$ aventura con Argentaria testimonia de nuevo la escasa lealtad de Rogel en asuntos de amores. Luego de conocerla el caballero piensa: «iAy, qué grande es la fe que a mi señora tengo!, pues la hermosura d'esta donzella y su gracia me semeja, que aunque d'ella fuesse requerido, no bastaría a vencer mi libertad, que de tantas donzellas y dueñas en la fe de Leónida y de Persea me pudieron vencer», pero prontamente, mientras está a solas con Argentaria, se despierta el deseo, que le ocasiona un combate interior: «El cual como assí se vido, la fuerça de su hermosura le combatía por una parte, y la fidelidad que a Arquisidea le parecía dever, resistía la presente fuerça, y juntamente le combatía, parecelle que compañía de tan poca edad no pedía tanta cordura para que alguna cosa dixesse de las que convenían a cavallero mancebo estando de tan suerte con tan hermosa donzella» Cit. por M. ${ }^{\text {a }}$ del Pilar Villaverde, Florisel de Niquea (Cuarta parte, Libro I). Guía de lectura, Alcalá de Henares, Centro de Estudios Cervantinos, 2002, p. 26.

${ }^{35}$ Para esta ordalía, véase Martín Romero, «Del fin'amors al neoplatonimo», art. cit., pp. 140-141 y su guía de lectura Florisel de Niquea (cuarta parte / Libro II), Alcalá de Henares, Centro de Estudios Cervantinos, 2005, p. 20

${ }^{36}$ Cit. por Emilio Sales Dasí, ob. cit., p. 54.

${ }^{37}$ Justina Ruiz de Conde escribió una bella reflexión sobre este personaje en El amor y el matrimonio secreto en los libros de caballerías, Madrid, Aguilar, 1948, pp. 253-268. 
y anuncia en toda su dimensión la figura de don Juan. Su avidez sexual y la búsqueda de la satisfacción de ésta es su rasgo más marcado, pues como le dice a un ermitaño que le advierte sobre el peligro de la lujuria «estas son obras de humanidad á las cuales no se pueden huir, y el desseo es tan delicado, que echa mano de las cosas que el corazón se aficiona» (p. 199). Su derrotero amoroso comienza con Arnalta, princesa de Navarra, en quien el caballero «siempre tuviera los ojos en ella y la voluntad no muy lejos» (I, 66, p. 118). El encuentro sexual, que se produce la primera noche de la estancia del caballero en el castillo, no sucede sin embargo como una recompensa a una acción realizada por el Caballero del Salvaje ${ }^{38}$; es más bien el resultado de las palabras atentas del caballero acerca de la belleza de la dama, que según él se equipara a la de Miraguarda, la doncella que permanece en una torre y que da origen a la aventura que lleva su nombre. La coquetería y los «falagos», aunados a una atracción mutua -no en balde, Arnalta es caracterizada por Moraes como una mujer liviana y de una marcada avidez sexual-, no propician como podría suponerse el comienzo de un proceso de amores, pues luego de ocho días de estar a su placer el caballero abandona el castillo «enhadado» $\mathrm{y}$ «olvidado de tornar», dejando a Arnalta «deseosa» y «alegre de sus amores». El incumplimiento de la promesa de regresar a visitarla tendrá como consecuencia el enfado de la princesa de Navarra con Floriano, disgusto que se constituirá en un sentimiento recurrente en las mujeres que más adelante quedarán atrapadas por el efecto de su hechizo seductor. Así, la iniciación sexual imprime unas particularidades que aparecerán en otras de las conquistas del caballero: 1) la atracción irresistible que la belleza femenina ejerce en él y que enciende su deseo, 2) la importancia de la conversación y de las palabras para que la doncella en cuestión acepte sus requerimientos, 3) la utilización del engaño para lograr la satisfacción del deseo, 4) las rápidas manifestaciones de su desinterés una vez ha aplacado su apetencia sexual, lo que finalmente 5) da origen a un sentimiento de enfado y desengaño por parte de la doncella cuando ésta (o éstas) descubren la deshonestidad amorosa de Florineo.

Este bosquejo se repetirá en su siguiente trofeo amoroso: Targiana, hija del soldán de Babilonia (I, 86), por la que inmediatamente se siente atraído a causa de la belleza de la doncella y al «poder de la conversación de cada día, que le obligó á se perder por ella, cosa contra su condición, que para con ellas solía tener libre» (p. 148). Como ha sucedido con Arnalta, el sentimiento es recíproco, pues una vez conformes sus voluntades «tuvieron tanto poder que

\footnotetext{
${ }^{38}$ No me parece casual el uso del apelativo Caballero del Salvaje, pues de acuerdo con la tradición folclórica los salvajes eran los símbolos de una pulsión erótica desbordada, de los instintos y las pasiones. Cfr. Roger Bartra, El salvaje en el espejo, México, UNAM-Ediciones Era, 1992.
} 
vinieron al efecto dellas, á donde Floriano llegó al fin de lo que esperaba, y entró en el comienzo del aborrecer, cosa que muchas veces tienen los hombres por natural» (p. 148). Sin embargo, una vez cumplido el deseo, la atracción en Floriano dura poco y va «perdiendo el cuidado», razón por la cual «quiso con razones fingidas hacerla creer que entonces más que nunca estaba metido en ellos, [...] y la satisfizo tanto cuanto vio que era menester» (p. 148). El episodio con la hija del soldán de Babilonia hace patente la conducta reprochable y poco escrupulosa del Caballero del Salvaje, pues acepta que la muchacha engañe a su padre para poder salir de la corte, haciéndole creer que mantiene su amor por ella. De esta manera Targiana abandona el entorno familiar, llevando como su cuidador a Floriano, quien no parece preocuparse por ella cuando es raptada por Albanis, hijo del rey de Dinamarca, mientras él combate con su hermano Palmerín sin reconocerlo. Como es natural, su desprecio enciende en Targiana un deseo de venganza que no se aplacará ni con su boda con Albaizán y que recaerá más adelante en Leonarda, el siguiente objeto de deseo del caballero. La princesa, que había sido desencantada por Palmerín y conducida por el caballero a la corte de Constantinopla, con su gracia y desenvoltura somete a Floriano y él «puesto que su libertad hasta entonces libre tuviesse mala de someter á cuidados enamorados, en aquella hora no pudo tanto ser libre que en alguna parte no se hallasse combatido dellos» (II, 10, p. 212). Pero su carácter mudable no le permite ser fiel y el amor que siente por Leonarda no resiste el embate de la belleza de cuatro doncellas que lo reciben en un castillo adonde es conducido por engaño para vengar en él la muerte de los gigantes Calfurnio y Calboldán. La atracción que Floriano siente es incontrolable «y assí ponía los ojos en las unas como en las otras, porque á todas le guiaba la voluntad, que esto es natural de hombres de voluntades libres» (II, 12, p. 217). En el castillo lo espera también la jayana Arlanza, hermana de los gigantes, que olvida el rencor cautivada por la belleza del caballero y se enamora de él. El episodio no deja de ser curioso, porque el caballero, siguiendo sus inclinaciones y creyendo que «podría su desseo tener efecto» pues «la disposición de su persona [Arlanza], la compostura de los miembros, la grandeza del cuerpo, la singular gracia y aire, le hacían dessear, creyendo que si della podría haber fruto, sería hombre de grandes obras» (II, 12, p. 218) una vez que la jayana lo salva de la muerte Floriano deja de lado su primera inclinación y no busca la satisfacción de su deseo; de hecho es la primera y única vez que el caballero podrá dominar su impulso sexual. El signo innovador y revolucionario del personaje de Moraes que ha sido resaltado por Ruiz de Conde ${ }^{39}$, quizá no

\footnotetext{
${ }^{39}$ Para Ruiz de Conde, la actitud de Floriano con Arlanza es un rasgo de regeneración en el caballero y se pregunta: «¿Por qué? ¿Es que la tendencia donjuanesca de la obra no podía salir triunfante en ella 
alcanzaba todavía para permitir la relación entre dos personajes de desigual condición y por ello se limita a un pequeño devaneo sin mayores consecuencias, aunque sí para una relación amorosa con una pagana, a la que miente y desdeña, porque como le dice Polinarda a Leonarda para salvar la vida del cautiverio es válido el engaño y el olvido:

¿creéis vos que lo que Foriano usó con Targiana se pueda usar con vos? Habíaseos de acordar que el amor para con ella no era lícito ni honesto, más que en cuanto le fuesse necessario, que él estaba cautivo en poder del turco, y para salir no tuvo otro remedio sino el que ella le dio; pues después ¿no queréis que se le acordasse que era cristiano y ella mora, y que con hacer su voluntad ofendía á Dios? (II, XXI, p. 246).

La partida del caballero con Arlanza y cuatro de sus doncellas da pie a su caracterización de Floriano como el Caballero de las Doncellas, pues hermoso y galante viaja por el mundo acompañado de nueve de ellas ${ }^{40}$, a las que «conversaba con los ojos y con las palabras por igual, por no dejar a nenguna descontenta» (II, 15, p. 227) «acostumbrado siempre a no dar su posesión a ninguna», dándose maña para satisfacerlas y engañarlas a todas a la vez. En su compañía, el Caballero del Salvaje llega a la ciudad de Toledo a la corte del rey Recindos a quien le solicita permiso para justar con los caballeros de su corte en la defensa de la hermosura superior de sus acompañantes. Allí vence a cuantos participan en la aventura. Sus proezas en armas acrecientan el deseo de su séquito femenino, «pues cada una se perdía por él y él por todas, que assí era su costumbre» (II, 23, p. 251) y sobre todo se aguzan en Arlanza, que vencida de sus amores, acude al lugar donde el caballero ha decidido pasar la noche, en medio de una agradable floresta; allí el caballero le confiesa que su primera intención, antes de verse obligado a ella por cortesía, fue «hacer lo que agora a vos vuestra voluntad os pide», pero que ahora no quiere agradecerle con «cosa que tiene el placer breve y el pesar largo» (II, 13, p. 251), respuesta curiosa para quien se ha concentrado justamente en la consecución del placer sexual y el «breve deleite». Desairada por el caballero, Arlanza regresa al lugar donde dormían las demás y su doncella de confianza, la más bella, le promete indagar las razones del rechazo. El talante disoluto del caballero hace aparición pues sorprende a Polifema con una declaración de amor en la que, otra vez, demuestra una pasmosa habilidad con la palabra $-\mathrm{y}$ con las manos-y la escasez de escrúpulos:

porque don Juan es un tipo barroco y Floriano no pasa de ser un precursor del mismo?», ob. cit., p. 261.

${ }^{40}$ Se trata de Arlanza y las cuatro doncellas que la acompañan -Polifema es el nombre de una de ellas-, más otras cuatro (Armelia, Julianda, Sabelia y Articia) ganadas en unas justas con sus respectivos aguardadores. 
«Señora, dijo el del Salvaje, [...] ¿Qué escusa daréis vos á no acordaros de mí, sabiendo que os lo merezco? [...] Vos hacé lo que quisiéredes, trátame como á vos vuestra condición os enseñare, que tanto os quiero y amo, que con ningún agravio lo dejaré de hacer». Y como entre unas y otras palabras á las veces le pusiesse las manos en la ropa y le tomasse las suyas, y la hallasse reposada, sin accidentes ni respuestas ásperas, soltó más las riendas á la plática y tomó mayor atrevimiento en el tocar, de manera que dándole la respuesta que desseaba, la tornó a enviar con ella hecha dueña, cosa que hasta entonces no fuera. $Y$ con el contento que llevaba, hizo mil castillos de viento a su señora de cosas en que no hablaron. Y él de allí adelante durmió su sueño reposado, que hasta entonces el desseo de passar por aquélla aventura se lo estorbara» (II, 23, p. 252) .

Más signos de su condición licenciosa y desenfrenada enseña el caballero durante el trayecto que lo conducirá a la corte francesa, pues ante los celos de Polifema, se dedica a las otras doncellas «que con unas platicaba, con otras burlaba» (II, 24, p. 253) y muda prontamente su parecer, evidenciando así otro de los rasgos de los seductores: la exigua constancia y escasísima duración del interés en su objeto de deseo una vez que éste ha sido satisfecho:

El caballero del Salvaje puso luego la afición, en otra parte, y por más contentallas á todas, sin contradición de ninguna tomaba cada día la suya para conversar; paresce que les paresció tan bien, ó sus palabras tuvieron tanta fuerza, ó la disposición dellas fue tan poca, que antes que llegassen á Almaurol que todas iban arrepentidas, sin unas saber de las otras. Assí sabía tomar las horas á tiempos, que para todo tenía lugar; acabado esto, llególe desseo de dejallas, que esta era su condición (II, 24, p. 253).

Sin embargo, la valentía de Florineo no es suficiente para compensar su deslealtad, que tiene como consecuencia que las doncellas se sientan desengañadas y comiencen a desamarlo. Polifema es quien señala el carácter voluble de Floriano y lo tilda de desamorado, pues es «persona libre y en quien el amor tenía poca parte para le hacer bien ni mal» (II, 26, p. 259). Artisia, otra de sus acompañantes, dice estar tan desengañada de su condición, que no se tiene de «vencer más della, mas antes, si los caballeros buscan quien quiera dejar amores viejos por nuevos», (II, 28, p. 266) allí está ella para hacer el trueque, manifestación a la que se suman las cuatro doncellas que ganara

\footnotetext{
${ }^{41} \mathrm{La}$ alusión que se hace aquí al insomnio que produce el deseo amoroso será una constante en el personaje pues el síntoma se acentuará en el aventura de las cuatro damas francesas que sucesivamente van a visitarlo sin acceder a sus requerimientos amorosos. Nótese que, en este caso, el síntoma se alivia una vez se ha saciado el deseo.
} 
Floriano en las justas contra sus aguardadores. Finalmente, las desavenencias conducen a la separación y el caballero toma rumbo hacia Navarra dejándolas en la corte. Ya solamente con cuatro de sus doncellas, Florineo arriba a la corte de Francia donde las damas Mansi, Telensi, Latranja y Torsi han establecido una aventura para difundir la fama de su belleza por todo el mundo y determinar de una vez por todas cuál de ellas era la más hermosa. Un día de gran calor, cuando cabalgaba por la ribera de un río, Florineo «vio tantas damas y tan galanas en tal estremo hermosas, y comenzó dessear servillas á todas, que con menos no se contentara» (II, 38, p. 296) y en efecto se declara «enamorado hasta la muerte de todas». La aventura de las cuatro damas francesas será la prueba de fuego para el caballero, que ya iba de retroceso de su senda seductora y buscaba el reposo en el amor de Leonarda. Simbólicamente significará el peor de los castigos, pues su carácter licencioso e incontinente, su condición de mal amador tendrán la recompensa merecida cuando sea incapaz de seducir a las cuatro damas con sus argucias habituales y la delicadeza de su conversación enamorada. Así lo había pronosticado el ermitaño: «Vos seguí el mundo, que es ancho y grande, que en fin él os dará el pago, que ninguno le servició que tarde ó temprano no se lo diesse» (p. 200). La aventura que debía conducirlo a la gloria de haber logrado conquistar a las damas, lo doblega por completo cuando se siente, por primera vez, desdeñado y fracasado. El golpe de gracia se lo da Torsi, la última y más bella de las cuatro, después de obligarlo a descubrir su verdadera identidad cuando le arrostra en la cara su fama:

- Señor caballero, -respondió ella-, si palabras me hubiessen de engañar, tales son las vuestras que lo pudieran hacer; mas quien servio á Targiana y á Arnalta, y las dejó quejosas, bien será que halle alguien de que se queje; vuestros cuidados os acompañen, que yo de alegre de acabar mi empresa no puedo más detenerme (II, 46, p. 323)

De esta manera, Floriano, el más liviano de los amadores, aquel para quien tocar la mano de la dama era poca paga, el más engañador de todos y que había hecho toda suerte de caballerías y de sutiles conversaciones para rendir la voluntad de las francesas con las mismas palabras y las mismas declaraciones es derrotado con idénticas armas de seducción. Su fracaso es enorme y despiadado, tanto que lo obliga a renegar y a prender de lo pasado: queda así abierta de par en par la puerta para el matrimonio con Leonarda. Ya ha asimilado que no puede continuar con «un amor gentil», como le reprocha una dueña francesa, que reparte en «muchos lugares», que el único camino posible es el amor de Leonarda y que, por tanto, debe acomodarse a 
los códigos dominantes. El espacio se ha cerrado y el colofón de su andadura amorosa no puede ser otro que el matrimonio, un vínculo que lo transformará radicalmente pues «si hasta allí vivió essento y libre, de allí adelante de muy enamorado della quedó tan cautivo, que parescía no ser él. Desto no se espante nadie, que la edad y el casamiento tienen por condición mudar las costumbres; quien con cualquiera destas cosas no la mudara, tendrá hasta la muerte con la que nasció» (II, 50, p. 331).

El recorrido incesante, sin destino y sin puerto de llegada en un único amor, ese que ha llevado a estos caballeros a destacarse por sus amores efímeros e inconstantes, a demostrar en el camino su incapacidad de sentirse atraídos por una sola mujer, dominados por las pasiones y los instintos y por tanto abocados a vivir una sensualidad desbordante que les impide ser representantes del arquetipo heroico aun cuando sobresalgan en las armas, tiene también un puerto de llegada que reconduce ese ímpetu sexual hacia el matrimonio: Galaor, Rogel y Floriano son absorbidos e integrados en las pautas y las normas del amor caballeresco y de la moral imperante que hacía de la relación conyugal el marco propicio para el dominio de las pasiones exacerbadas. Acaso como ya anotaba Ruiz de Conde, la revolución y la rebelión contra la deificación de la mujer, contra la limitada vivencia de la experiencia erótica reducida al matrimonio, que personifican estos seductores, debía llegar a su fin y se hacía necesario acotar estos caballeros a las normas. Pareciera, así, que lo que en ellos significa el matrimonio se transformará en el siglo XVII en la muerte de don Juan.

No sólo el fin de su andadura hermana a los seductores que hemos acompañado en su trasegar; otras estaciones del camino los unen, de la misma manera que comparten algunas circunstancias vitales que evidencian sus ligerezas y devaneos. Muchas de sus aventuras amorosas son por supuesto recompensas de sus actuaciones en armas, de la ayuda ofrecida a una doncella o dueña en peligro; otras, en cambio, son el resultado de un impulso erótico irresistible, donde prima el arte de la galantería, la conversación cortés y delicada y se pone en marcha el mecanismo de la seducción; Galor, Rogel y Florineo seducen, son sujetos y no objetos de deseo, aun cuando el deseo sea compartido por la doncella o la dueña de turno; prevalece así la atracción erótica, el amor-pasión, que no admite aplazamiento y en el que no hay scala amoris ni mucho menos continuidad en el vínculo. Estas relaciones esporádicas, sin embargo, no tienen consecuencias, a excepción de Rogel que engendra unos cuantos hijos, y ni siquiera afectan la relación con la dama en el caso de que exista ya sea por el engaño mantenido, ya sea porque una voz amiga o una ordalía alivian sus angustias y sus celos. Estos mujeriegos, que 
tienen incluso el atrevimiento de someterse a ordalías aún cuando saben que no saldrán bien librados a causa de su deslealtad amorosa, son una muestra más de la pluralidad en la casuística amorosa de los libros de caballerías, pero también una prueba de cómo, para el siglo XVI, hasta el más empedernido de los infieles podía redimirse, pues como bien decía Moraes, «los hombres que mucho tiempo fueron libres, si se vienen á enamorar son más enamorados que los otros que lo acostumbran» (II, 51, p. 336).

Recibido: 20/05/2011

Aceptado: 15/07/2011

\section{$\cos$}

RESUMEN: Este artículo aborda el motivo del caballero seductor y mujeriego, antecedente del Don Juan de Tirso de Molina, que corresponde en el catálogo de Stith Thompson al motivo T10.4 (G), "Man continually falling in love". Se hace una revisión de los herederos de Gauvain artúrico en los libros de caballerías castellanos, con especial atención a Galaor en el Amadís de Gaula, Rogel de Grecia del Florisel de Niquea y Floriano del Desierto del Palmerín de Inglaterra para descubrir los rasgos que los hermanan y que los hacen transgresores del ideal de amor cortés de fidelidad y servicio a una sola dama.

ABSTRACT: This article approaches the motive of the seductive and womanizer knight, antecedent of Tirso's de Molina Don Juan, which corresponds to the motive T10. 4 (G) on Stith Thompson's Index, "Man continually falling in love". It makes a revision of arturic Gauvain's heirs on the castilian romances of chivalry, with special attention to Galaor on the Amadis de Gaula, Rogel de Grecia from Florisel of Niquea and Floriano del Desierto from Palmerín de Inglaterra, in order to discover the twinning features among them, that also make them transgressors of the ideal of courtly love and service to one lady.

Palabras clave: Libros de caballerías. Seducción. Caballero mujeriego. Amadís de Gaula. Florisel de Niquea. Palmerín de Inglaterra.

Keywords: Chivalric romances. Seduction. Womanizer knight. Amadís de Gaula, Palmerín de Inglaterra. Florisel de Niquea. 